PREPRINT EXTENDED ABSTRACT

Presented at the I\&EC Special Symposium

American Chemical Society

Atlanta, GA, September 17-20, 1995

\title{
ACTIVITIES OF THE INEL SAMPLE MANAGEMENT OFFICE: RESULTING IN EFFICIENCY AT THE INEL
}

\author{
Clifford S. Watkins \\ Shauna A. Hoiland \\ Lockheed Martin Idaho Technologies \\ Idaho National Engineering Laboratory \\ P.O. Box 1625 \\ Idaho Falls, ID 83415-3910
}

The Idaho National Engineering Laboratory (INEL) Sample Management Office (SMO) was formed as part of the EG\&G Idaho Environmental Restoration Program (ERP) in June 1990. Since December 1991, the U.S. Department of Energy (DOE) Idaho Operations Office (DOE-ID) division directors for the Environmental Restoration Division and Waste Management Division have supported the expansion of the INEL ERP SMO into the INEL site-wide SMO. Under the new INEL consolidated contract, awarded to Lockheed Martin Idaho Technologies (LMIT), the site-wide SMO is being implemented.

The INEL SMO serves as a point of contact for multiple environmental analytical chemistry and laboratory issues (e.g., capacity, capability). The SMO chemists work with project managers during the planning phase of projects to help develop data quality objectives, select appropriate analytical methods, identify special analytical services needs, identify a source for the services, and ensure that requirements for sampling and analysis (e.g., preservatives, sample volumes) are clear and technically accurate. The review of sampling and analysis plans (SAPs), generated for ERP activities, by SMO personnel is coordinated by the LMIT Environmental Operations Branch Internal Review Committee.

The INEL SMO processed 5,500 analytical requests in fiscal year (FY) 1992, 9,700 in FY 1993, and 9,000 in FY 1994. The term "analytical request" defines a request for a specific analysis, rather than "sample," which represents containers collected at one location (which usually have multiple analytical requests). To date, for fiscal year 1995 the INEL SMO has processed approximately 5,000 analytical requests.

Currently, the INEL SMO assists LMIT Procurement to obtain and monitor laboratory services for all INEL ERP contractors, the INEL Drinking Water Monitoring program, most LMIT Waste Management projects, most LMIT Technology Development program samples, and most LMIT Work For Others projects.

Analytical services are subcontracted through the use of master task agreement (MTA) subcontracts. The INEL SMO prepared statements of work (SOWs), developed mandatory requirements for the requests for proposal, and reviewed proposals received for the MTA subcontracts awarded to eight laboratories. These subcontracts recently expired and the SMO is utilizing lessons learned during the last subcontract performance period to enhance the MTAs for the next solicitation and award process. The enhancements to the subcontracts will ensure greater 
flexibility to meet the broad requirements of the SMO customers. The 1995 MTA subcontracts will be awarded to at least three laboratories for analysis of mixed and "cold" samples for inorganic and organic analytes, and two laboratories for analysis of environmental and waste samples for radionuclides. Awards will be made to ensure adequate laboratories capable of receiving radioactively contaminated samples, and laboratories certified by the State of Idaho for drinking water analyses are available. The SMO chemists prepare project-specific work scope statements (task orders) for the laboratories under the MTA subcontracts to ensure that project-specific requirements [e.g., additional quality control (QC), abbreviated data deliverable] are addressed in addition to standard requirements of the MTA SOW. The MTA subcontractors provide pricing for most analytical methods required by INEL projects. By preparing specific task orders for each project, the laboratory offering the lowest price for the analyses required (assuming the quality of their deliverables meets SMO expectations, and their capacity to accept the samples is not exceeded) is issued the task order. This results in a significant cost benefit and savings to the project. The cost benefit is realized by the fact that SMO quality requirements must be achieved for the laboratory to continue to receive task orders. The savings is realized by the fact that the lowest priced laboratory offering the required analyses is used.

In addition to the MTA subcontracts, the INEL SMO identifies sources for special analytical services. For example, the INEL SMO worked with Procurement to obtain mobile analytical laboratory services for projects requiring short turnaround time for analytical results. The procurement process for all analytical services, including mobile laboratories, includes an on-site audit of the facility.

The INEL SMO monitors the performance of the laboratories in several ways. An automated sample and data tracking system produces performance indicator (PI) charts, which show the average turnaround time for data returned from laboratories and the percentage of the samples analyzed within the method-specific holding time. These data are tracked on a per laboratory and a per analysis type basis. This allows the SMO to identify areas of weakness for a given laboratory and avoid potential problems. Additional PI charts are produced that reflect data package deficiencies. Specific data package deficiencies that are tracked include inconsistent data reporting forms, incomplete data reporting forms, missing forms, and inconsistent chain-of-custody documentation. Additional efforts to achieve a more comprehensive laboratory oversight program has begun under the SMO's Analytical Services Performance Evaluation Program (ASPEP) (see separate paper in these proceedings).

The INEL SMO has implemented an efficient and structured process for subcontracting analytical data review and validation through the use of an MTA. The INEL SMO prepared a SOW, which includes standard operating procedures (SOPs) for data review. Consulting firms perform validation using INEL SMO procedures to ensure consistency of the deliverable. The analysis types that are currently supported by the data validation subcontractors include gas chromatography analysis for semivolatile organics (including pesticides and polychlorinated biphenyls), gas chromatography/mass spectrometry (GC/MS) analysis for volatile and semivolatile organics, inorganic analyses, and radiological analyses.

The INEL SMO uses several tools for measuring and monitoring its own performance. The most demanding customer requirement originates from the INEL ERP Federal Facility Agreement and Consent Order (FFA/CO). The FFA/CO includes a requirement to have "quality assured data" delivered to the Idaho Department of Health and Welfare (IDHW) and EPA "within 75 not to exceed 120 days from collection." Quality assured data means that data validation is complete and documented. The INEL SMO tracks performance against this FFA/CO requirement. It is the goal 
of the INEL SMO to deliver data to the project managers within 65 days to ensure that the data can be transmitted from DOE to the IDHW and EPA within 75 days.

The INEL SMO incorporates expertise from other INEL organizations. The LMIT Quality Assurance and Oversight Directorate and Coleman Energy and Environmental Systems quality engineers provide certified lead auditors for laboratory audits. Data storage and Geographical Information System support for the Environmental Restoration Program data are provided by the Environmental Restoration Information System (ERIS). A number of data management tools and capabilities used by the SMO are provided by the Integrated Environmental Data Management System (IEDMS), which is fully supported by the LMIT Software and Electronics Engineering Department.

The IEDMS provides an efficient and accurate means of sample tracking; developing an SAP database; generating sample labels, tags, and sampling guidance forms; performing and supporting analytical data verification and validation (V\&V); generating completeness reports, producing QC and results tables, and PI charts. All capabilities are either partially or totally automated.

The IEDMS integrates the many diverse elements of an environmental sampling and analysis activity into a single comprehensive data management package. The IEDMS serves as a development and production (processing) tool for the planning, sampling and analysis, and data V\&V stages of an environmental program.

Beginning with its assignment of unique sample identification numbers, the IEDMS performs sample tracking throughout all phases of a project. Automated status, discrepancy, and completeness reports can be generated at any step in the project. The discrepancy reports identify any inconsistencies in the sample tracking data by making a comparison of the data resident at different stages of the project (e.g., planned, collected, and analyzed samples are compared for consistency).

Initially, the SAP is entered into a predefined but flexible database structure. The SAP application produces a SAP table. The SAP table contains a list of samples and information, including sampling location, depth, planned analysis, and the required level of analytical method data validation. Once the SAP database (table) is finalized, it is used as input to automatically produce sample labels and tags, with or without bar code identification. In addition, sampling guidance forms can be produced for the field sampling team. These forms include information such as sampling location, requested analysis, container types, and preservatives. The barcoded labels can be used to produce chain-of-custody (COC) forms in the field using a pen-based portable computer. The COC application is integrated with the SAP table application ensuring that no transcription errors of sample identifications, sample locations, or preservatives used occur when completing the COC form. Using computer generated COCs also makes the forms much more legible at the laboratory receiving the samples.

Another capability of the pen-based computer is an interface with Global Positioning System (GPS) electronics. Using the GPS capability, the planar coordinates of the sample location are surveyed in the field and captured by the SAP table application. These location data are then concatenated with all analytical results data to ensure accurate location data are uploaded to ERIS.

Upon completion of the field sampling, selected data from chain-of-custody records and the various field log books are captured electronically. At this point, an automated completeness report can be produced that compares the requirements of the SAP to what was actually collected in the field. 
The IEDMS supports a number of analytical SOWs some of which are as follows: the EPA's 1987, 1988, and 1990 Contract Laboratory Program (CLP) SOW for Organic Compounds (OLM01.9) and Inorganic Analysis (ILM03.0); and INEL SMO SOWs for Organics and Inorganic and Miscellaneous Classical Analyses.

Data entry is typically performed through the use of electronic data screens that mirror the actual data forms. Exceptions are data received in either IEDMS data structures or EPA CLP Format A diskettes. IEDMS has the capability to either import or export EPA CLP Format A data files. This year, the IEDMS personnel are developing the capability to capture electronic data from analytical laboratories using the Department of Energy Environmental Management Electronic Data Deliverable Master Specification (DEEMS). The DEEMS is an interagency (Department of Defense, DOE, and EPA) cooperative effort to define an electronic data deliverable format that is flexible enough to capture data produced from any analytical method for any site-specific data management system.

After initial data entry has been completed for a Sample Delivery Group (SDG), initial comprehensive QC tables can be generated. These QC tables are unique presentations of the complete set of results and QC data contained on the forms provided as part of a data package (SDG). The QC tables present the data chronologically, i.e., consistent with the order in which the samples were analyzed and QC checks were performed. The QC tables used to support data V\&V are commonly included as an appendix to reports, and facilitate an independent assessment of results and conclusions made for a study. When all data packages are finalized for a particular type of analysis (e.g., inorganics, semivolatiles, or volatiles), results tables are automatically produced.

The INEL SMO represents the INEL for the DOE Headquarters Office of Transportation, Emergency Management, and Analytical Services (EM-26) Field Sample Management Program (FSMP) activities. The EM-26 Analytical Services Program Five-Year Plan called for the development of a SMO network. The network consists of SMO(s) at each DOE facility having an EM mission, and a National Sample Management Program (NSMP) for identification of national level issues that affect DOE analytical services resource management.

The benefits of having one SMO at a DOE facility are:

- Cost savings by reducing duplication of effort for analytical and data validation subcontract awards, laboratory audits, and approvals

- Centralized performance monitoring for all analytical services used by the site

- Centralized storage for data that are used for environmental project decisionmaking

- Deliverables that are consistent with the requirements of each program

- A clearing-house for information regarding analytical services issues at the site

- Site wide integration with the DOE Headquarters EM-26 Analytical Services Program.

Work supported by the U.S. Department of Energy, Assistant Secretary for Environmental Management (EM), under DOE Idaho Operations Office Contract DE-AC07-94ID13223 


\section{DISCLAIMER}

This report was prepared as an account of work spoasored by an agency of the United States Government. Neither the United States Government nor any agency thereof, nor any of their employees, makes any warranty, express or implied, or assumes any legai liability or responsibility for the accuracy, completeness, or usefulness of any information, apparatus, product, or process disclosed, or represents that its use would not infringe privately owned rights. Reference herein to any speciric commercial product, process, or service by trade name, trademark, manufacturer, or otherwise does not necessarily constitute or imply its endorsement, recommendation, or favoring by the United States Government or any agency thereof. The views and opinions of authors expressed herein do not necessarily state or reflect those of the United States Governmeat or any agency thereof. 


\section{DISCLAMIER}

Portions of this document may be illegible in electronic image products. Images are produced from the best available original document. 